\title{
A POLÍTICA DE SAÚDE LGBT NO SUS: contribuições para o Serviço Social $^{*}$
}

\author{
Marco José de Oliveira Duarte
}

\section{Introdução}

Ao tomarmos o campo dos estudos de gênero e sexualidade, tendo como referência a população de lésbicas, gays, bissexuais, travestis, transgêneros e transexuais (LGBT) e a política de saúde, observa-se um processo histórico em construção, que se materializa na política de saúde LGBT. Na análise dessa relação emerge expressões discriminatórias nos quais esses sujeitos, seus corpos, gêneros e sexualidades são tratados, e, em decorrência disso, que essas demandas são traduzidas como necessidades em saúde, instituindo, assim, a política nacional de saúde integral de LGBT.

O objetivo deste capítulo é introduzir algumas questões teórico-conceituais sobre o universo desse segmento, tematizando as políticas e direitos de LGBT e por fim, tratar desta política equitativa, enquanto uma política de saúde integral no âmbito do Sistema Único de Saúde (SUS), tomando os elementos que a caracterizam, como, em particular, o uso do nome social, o processo transexualizador e as questões sobre o acesso aos serviços, a partir das vulnerabilidades em saúde dessa população.

Analisar, portanto, o tema da saúde de LGBT é colocar na cena do debate questões que se relacionam, interseccionam e articulam, principalmente, porque o que está sendo demandado por essa população é a proteção à vida por parte do Estado. O mesmo Estado que, através da gestão pública, tem um discurso oficial de desproteção a esses sujeitos, apesar de um leque de normativas jurídicas e legais em diversos âmbitos setoriais do mesmo. Contudo apesar das poucas conquistas de políticas e direitos, protagonizada pelos movimentos sociais LGBT, essas se mostram frágeis, precárias e, particularmente, ameaçadas na sustentação política e econômica de suas políticas públicas voltadas para a população LGBT.

Assim, ao tomarmos o cerne desse debate, pretende-se tratar de dados concretos dessa realidade, a partir de uma análise histórica e crítica, de como essa demanda social de LGBT vem sendo respondida pelo Estado no seu "fazer viver, deixar morrer" (FOUCAULT, 2008), revelando que o que está em jogo é o tema do poder em seus mecanismos de intervenção e de constituição de dispositivos e estratégias. Portanto, trata-se de perguntar, em seus mecanismos, seus efeitos e suas relações, pelos dispositivos de poder que são exercidos nos diferentes domínios da sociedade, mas em particular, para nossa análise, sobre a não responsabilização do Estado em efetivar de forma concreta a defesa, a cidadania e dos direitos de LGBT.

Desta forma, pensa-se que essa produção possa vir a contribuir para a reflexão crítica sobre alguns desafios ético-políticos que se colocam para o trabalho profissional de assistentes sociais no processo de trabalho em saúde e na garantia de políticas e direitos de LGBT, como usuários e usuárias do SUS que demandam acesso, atendimento integral e não discriminatório nas práticas de saúde.

${ }^{*}$ DOI- 10.29388/978-65-81417-27-7-0-f.128-144 


\section{Sobre a diversidade sexual e de gênero: questões teórico-conceituais e políticas}

Segundo os principais autores no campo dos estudos de sexualidade e gênero, como Foucault (1988), Scott (1995), Butler (2015) e Louro (2004), o conceito de sexualidade é uma construção sociocultural que engloba sexo, orientação sexual, identidade de gênero, erotismo, prazer etc. Desta forma, a sexualidade é experimentada através dos corpos, pensamentos, fantasias, desejos, crenças, valores, práticas e relações, no entanto, nem sempre todas essas dimensões são experimentadas ou expressadas.

Ao pensarmos sobre o conceito de gênero, o foco são as relações sociais, com seus marcadores sociais, culturais e históricos, não negando a materialidade dos corpos, mas percebendo que esses corpos só são compreendidos a partir de processos de significação cultural, histórica e politicamente construídos.

Portanto, as categorias de sexo e de gênero não devem ser analisadas de forma imutável e linear, já que ambas as configuram como construções históricas e sociais. Não existe um único modelo de homem ou mulher, que hegemoniza e normatiza os comportamentos na história. Fazse necessário romper com a lógica do sexo numa perspectiva binária, dicotômica e essencializada, baseada nas diferenciações biológicas.

Sob este prisma, toma a sexualidade para além da dimensão particular, considerando a pluralidade e a diversidade inerentes à manifestação do comportamento humano, evitando assim, a heterossexualização compulsória (RICH, 2010; BUTLER, 2015) e a cisgeneridade (SIMAKAWA, 2015) como normatividade da sexualidade humana.

Quando as instituições sociais reconhecem a sexualidade de homens e mulheres, tendem a direcioná-las para uma concepção baseada na heteronormatividade, no heterossexismo (FOSTER, 2001) e na cisgeneridade. Assim, apesar de se compreender que os direitos sexuais são um produto em construção, os sujeitos que divergem dessas normas impostas pela ordem sexual enfrentam dificuldades políticas, sociais e culturais para o seu reconhecimento e por isso demandam direitos LGBT nesse campo convencionado de diversidade sexual.

Direitos LGBT não tem a ver diretamente com a sexualidade, estão relacionados a questões previdenciárias, adoção, liberdade de movimento em espaços públicos ou mudança de nome e sexo na certidão de nascimento. Já os Direitos Sexuais, são considerados os processos sociais e políticos de estigmatização e discriminação que deles privam pessoas LGBT. São prerrogativas legais relativas a sexualidade ou a grupos sociais cujas identidades foram forjadas sobre formas específicas de desejos e práticas sexuais. Direitos de reconhecimento legal de relações afetivas sexuais, adoção conjunta de crianças, livre expressão de sua orientação sexual e/ou gênero em espaços públicos, redesignação do sexo e mudança do nome no documento de identificação civil, acesso a política de saúde específicas, proteção do Estado frente a violência por preconceito. Os direitos sexuais situam-se nessa complexa interface do público e do privado, que por um lado, refuta julgamentos morais em função do modo de obter prazer, que por outro, exige a liberdade para que os afetos e relacionamentos possam ser vivenciados e assumidos sem discriminação. Exige a garantia da proteção do Estado à vida 
privada e as escolhas pessoais, que coíbam as discriminações, violências e demais desigualdades nas relações pessoais e sociais. (CARRARA, 2010, p.135).

Todavia, percebemos que as diferenças sexuais e de gênero tendem a serem invisibilizadas e silenciadas pela sociedade, pois essa toma por base a existência de um único modelo hegemônico e universal na ordem sexual. Sendo assim, os dissidentes sexuais e de gênero, tornam-se "desviantes", diferentes, doentes ou em pecado, sofrendo com as formas radicais de apagamento, como violência e morte (CARRARA; VIANNA, 2006).

Contudo, isso só promove que cada um construa um entendimento estereotipado do outro que lhe é diferente. Como consequência, tem-se o fenômeno da invisibilidade ou ocultamento, produto desse processo de negação das diferenças, tanto nas esferas pública como privada, pautando as diferenças a partir de um modelo de existência, acrítico, conformando divisões e hierarquias sobre as sexualidades e os gêneros.

Assim, a livre expressão da sexualidade tem sido negada como um direito humano e a LGBTfobia tem-se revelado como uma das formas de violação de direitos, seja no interior da família ou das instituições sociais, colocando-se como obstáculo ao exercício de cidadania desses sujeitos, inclusive por parte do Estado. Ainda mais no contexto ultraneoliberal e de ultraconservadorismo.

No entanto, apesar dessa marca de opressão, dominação e de pânico moral, observa-se a afirmação e resistência de LGBT ao romperem com estereótipos atrelados social e culturalmente ao processo histórico das normas sexuais hegemônicas, sobretudo, ao paradigma da heterossexualidade compulsória e ao binarismo de gênero. Isso marcou os mais variados tipos de estigmatizações que servem para discriminar, perseguir, aumentar o sofrimento, a violência, ódio e morte, mas também a normatização da identidade (MACRAE, 2018). Desta forma, sujeitos LGBT ao se apropriarem desses mesmos rótulos, positivam seu uso, potencializando suas diferenças e identidades afetivo-sexuais e de gênero, como dissidentes da ordem e da moral sexual hegemônica.

Cabe destacar, nesse percurso histórico, que a homossexualidade foi submetida as técnicas de punição jurídico-penal (FOUCAULT, 1978) e de tratamento médico-moral dos loucos e degenerados, como forma de disciplinamento dos corpos desses sujeitos, como o internamento, o confinamento e o isolamento social, para fins de correção de suas práticas sexuais "não naturais" frente a hetreonormatividade como moral sexual. Por fim, essa é despatologizada, mundialmente, a partir da revolta de Stonewall, em 28 de junho de 1969, tanto pelas Associações Americanas de Psiquiatria (APA), em 1973, e de Psicologia (APA), em 1975, na revisão do Manual Diagnóstico e Estatístico de Transtornos Mentais (DSM), como pela Organização Mundial da Saúde (OMS), em 1990, na revisão da Classificação Estatística Internacional de Doenças e Problemas Relacionados à Saúde (CID).

No Brasil, o Conselho Federal de Medicina (CFM), em 1985 e o Conselho Federal de Psicologia (CFP), em 1999, já operavam pela lógica da despatologização, seguido pelo princípio da não-discriminação pelo Conselho Federal de Serviço Social (CFESS), em 2006.

O CFM através da Resolução no 1.652 , em 06 de novembro de $2002^{1}$, de fato garantiu a realização da cirurgia de redesignação sexual ou transgenitalização, já em curso no país de forma

\footnotetext{
${ }^{1}$ Essa Resolução do CFM substituiu a primeira sobre o tema, a Resolução no 1.482 , de 19 de setembro de 1997 , que autorizava de forma experimental a realização de cirurgia de transgenitalização do tipo neocolpovulvoplastia, neofaloplastia e ou procedimentos complementares sobre gônadas e caracteres sexuais secundários como tratamento dos casos de transexualismo.
} 
clandestina. Posteriormente essa legislação foi revogada pela Resolução no 1.955 , de 12 de agosto de 2010. Desse modo, esse procedimento deixa de ser crime de mutilação, como era entendido pelo CFM, mas a pessoa transexual deverá submeter a ordem psiquiátrica, visando identificar o diagnóstico médico, ainda, de transexualismo, pelo CID $10^{a}$ edição, em vigência, e a partir de 2022, de incongruência de gênero, com o CID-11 ${ }^{a}$ edição ${ }^{2}$, ou de disforia de gênero, pelo DSM $5^{\text {a }}$ edição, desde 2013.

Assim, com base na tal Resolução do CFM, é que o Ministério da Saúde institui o Processo Transexualizador (PT), em 2008, no âmbito do SUS, ao reconhecer, como determinação social da saúde, a orientação sexual e a identidade de gênero. Em 2013, em nova Resolução, o Ministério amplia o referido processo em curso no país, incorporando agora os homens transexuais. Observa-se que os sujeitos trans devem ser identificados pelo diagnóstico para terem acesso aos serviços de saúde do PT e desejar a cirurgia, revelando uma compreensão equivocada de tais normativas em relação às demandas em saúde das pessoas trans, enquadrado numa biocidadania da clínica médica (ROCON, 2021).

Esse aspecto legal, por um lado, afirma e legitima a identidade de gênero, independe do sexo biológico, configurando-se como conquista de direitos de transexuais, embora se esbarrem com alguns limites, como o acesso à rede e cuidados em saúde (DUARTE, 2014b). Mas também e mesmo assim, no discurso médico desse processo, que ainda se depara com a patologização de transexuais.

O CFP e o CFESS, em 2011, reconheceram a identidade de gênero e possibilitaram o uso do nome social por travestis e pessoas trans. Em seguida, a Ordem dos Advogados do Brasil (OAB) - Conselho Federal, em 2016 e o Conselho Federal de Enfermagem (COFEN), em 2017.

Todos esses marcos legais supracitados emergem historicamente no âmbito das instituições sociais, a partir das relações de poder, do embate de forças políticas e se constituem como conquistas e direitos para LGBT. Esse movimento serve para garantir o direito ao livre exercício da diversidade sexual e de gênero, sem discriminação e preconceito que setores conservadores insistem na patologia e no pecado ("cura gay") ${ }^{3}$, com tentativas e procedimentos terapêuticos para uma reversão para o que consideram à ordem natural das sexualidades, com enfoque na reprodução biológica das espécies humanas, focado na genitália como condicionante do gênero e suas expressões sociais (BENTO, 2008).

Sabe-se que boa parte dessa contestação e barreiras no interior da sociedade tem sido mais radicalizada pelos setores conservadores e com forte teor fundamentalista religioso, impondo uma leitura de doença, como que se algo deva ser tratado e a ser recuperado como nas "terapias de reparação" ou nas de "reorientação sexual", não levando em consideração o direito à autodeterminação dos sujeitos, suas existências, desejos e subjetividades diferentes e diversas.

Desse modo, as práticas sexuais são configuradas em concepções tanto de pecado, como de abjeto, ajustadas pelo moralismo. Assim, vão na defesa de um modelo heterossexual, isto é,

\footnotetext{
2 O CFM publicou em 09 de janeiro de 2020 a Resolução n ${ }^{\circ}$ 2.265, de 20 de setembro de 2019, que dispõe sobre o cuidado específico à pessoa com incongruência de gênero ou transgênero e revoga a Resolução CFM n ${ }^{\circ} 1.955 / 2010$. A primeira vista parece uma entidade vanguardista, mas na verdade e mais uma vez, o CFM assume uma função normativa que extrapola seu mandato e se sobrepõe aos seus deveres e responsabilidades. O CFM tem forte influência nas organizações dos serviços de saúde e nos cuidados de pessoas trans, inclusive sobre as regras de inclusão e exclusão de pessoas e procedimentos, sem questionamento por parte do Ministério da Saúde. (PRADO, M. A. M et al. 2020).

3 Termo utilizado como crítica ao movimento de psicólogos/as cristãos que no campo jurídico impetraram ação contra determinados artigos que pró́bem as terapias restauradoras por parte dessa categoria, conforme prescrito na Resolução CFP $\mathrm{N}^{\circ}$ 01/99. Derrotados pelo Supremo Tribunal Federal (STF) depois de certa querela. No campo legislativo, com representantes desse mesmo setor cristão, instituíram o Projeto de Decreto Legislativo (PDL) 234/11, na tentativa de sustar a aplicação dos mesmos artigos da referida Resolução, mas também foram derrotados e o referido PDL foi arquivado.
} 
para o que é aceitável, normal e padronizado na hierarquia dos valores morais sobre a sexualidade. Esse processo provoca um sofrimento psicossocial intenso para muitas LGBT, às vezes considerando-se anormal e desviante da normatividade dominante entre os sexos, as sexualidades e os gêneros.

Identifica-se que os debates e as produções científicas em torno das questões das sexualidades dissidentes que permeiam a esfera da diversidade humana, no seu sentido ontológico, tem se ampliado e se consolidado, entre disputas e campo de forças ético-políticas. Embora ainda se tenha ações discriminatórias e estigmatizantes sobre LGBT, quando são expostos a situações humilhantes e vexatórias, seja na esfera privada ou na esfera pública.

Não se pode negar ou fazer vista grossa para as implicações éticas e políticas desses segmentos, em suas singularidades na sociedade, marcada por vulnerabilidades específicas, seja na luta pela equidade do acesso à permanência no trabalho e emprego, sejam também nos serviços públicos de saúde, educação, assistência social dentre outros.

Mesmo que seja consenso que nos campos público e político haja a necessidade de enfrentamento da LGBTfobia, na medida que esses campos também são espaços de sociabilidade e de políticas públicas, contraditoriamente, portanto, esses lugares têm sido reprodutores da desigualdade, da opressão, da dominação e da segregação, bem como da discriminação e do preconceito por parte de agentes públicos.

É nesse contexto adverso e influenciado pelo ultraneoliberalismo, com retrocessos no campo das políticas e direitos sociais, que se precisa, e muito, afirmar a garantia de direitos e da democracia, rompendo com essas desigualdades sociais e econômicas impostas, ainda mais considerando, no caso da população LGBT, que vem sendo alvo constante de perseguição e ataques aos poucos e precarizados direitos e políticas recentemente constituídas, no processo de democratização do país e que se esvaem nesse momento histórico do Estado brasileiro.

Em síntese, problematizar a questão da diversidade sexual e de gênero, é afirmar que a sexualidade humana é permeada por valores e regras sociais que são determinadas de acordo com cada sociedade, grupo social e contexto histórico. Portanto, é através desse processo que as relações sociais e de poder vão se estabelecendo, assim como a produção e a reprodução de condutas e padrões sexuais, de sexualidade e gênero aceitáveis e conformados pelo sistema em vigor.

\section{Sobre políticas e direitos de LGBT}

As políticas e direitos da população LGBT vêm se situando de maneira fragmentada, apesar do Estado Democrático de Direito, essas conquistas e concessões estão sob a égide de uma LGBTfobia cordial (BENTO, 2017), na medida em que é regulado muito mais pela moral e pelos limites institucionais. Contudo, é nessa contradição imanente que se situam os diversos marcos legais e políticos que garantem o livre exercício da sexualidade e da identidade de gênero, mesmo que na frágil e precária cidadania de LGBT no Brasil contemporâneo.

Desta forma, é necessário registrar o marco histórico da política pública para os sujeitos LGBT, com a criação, em 2004, do Brasil Sem Homofobia (BSH): Programa de Combate à Violência e à Discriminação contra GLTB e Promocão da Cidadania Homossexual. Essa conquista marca a arena de luta pelo respeito às diferenças e o combate à discriminação e a violência que esse segmento vivência historicamente. De um total de 53 ações previstas no BSH, três integram o tópico Direito 
à Saúde: consolidando um atendimento e tratamentos igualitários (BRASIL, 2004). A principal delas talvez seja a formalização no mesmo ano, do Comitê Técnico de Saúde da População de GLBT do Ministério da Saúde, com o objetivo de estruturar uma Política Nacional de Saúde para essa população. Frente as outras duas ações: produção de conhecimento sobre saúde da população LGBT e a capacitação de profissionais de saúde para o atendimento a essa população.

Nesse contexto, toda a questão envolvida está em enfrentar o problema da homofobia (BORRILLO, 2010) e da transfobia no Brasil, que é patente, considerando todos os casos e dados sobre os ataques físicos, agressões sexuais, espancamentos, torturas e assassinatos, isto é, uma onda moral de discriminação, intolerância, ódio e de todos os tipos de violência que assola toda essa população.

Segundo o Grupo Gay da Bahia (GGB) a cada 25 horas uma pessoa LGBT é assassinada no Brasil ${ }^{4}$. Contudo, não se tinha, até 2011, nenhum dado oficial pelo Estado brasileiro sobre essas questões. Assim, começa-se a ter um banco de dados do poder público, tanto pelas denúncias no Disque 100, quanto pelas matérias nas mídias, o que resultou em três relatórios sobre a violência homofóbica no Brasil. Todavia, vale sempre relembrar que existe um subregistro desses dados, o que nos leva a observar que os relatos quantitativos representam a pequena parcela dos casos que são denunciados e notificados.

Desta forma, segundo o último Relatório publicado (BRASIL, 2013a), temos,

$73,0 \%$ das vítimas são do sexo biológico masculino; a identidade sexual das vítimas, manteve-se a maioria de não informados (46,8\%), seguido de gays $(24,5 \%)$ e travestis $(11,9 \%)$; pretos e pardos totalizam $39,9 \%$ das vítimas; a grande maioria das vítimas se concentra entre 15 a 30 anos, com 54,9\%; 36,1\% das violações ocorreram nas casas (...), seguido pela rua, com $26,8 \%$ das violações e outros locais com 37,5\% das denúncias; as violências psicológicas foram as mais reportadas, com $40,1 \%$ do total, seguidas de discriminação $(36,4 \%)$, violências físicas $(14,4 \%)$ e negligências $(3,6 \%)$.

Nesse sentido, essa população vivencia um quadro de intensa violação de direitos, portanto, esse tipo de iniciativa sem as atuais políticas e serviços sociais para tais sujeitos, tendem a permanecer o status quo de radicalização das violências e mortes, reinvindicação histórica dos sujeitos LGBT (DUARTE, 2011).

No entanto, é necessário destacar que no marco dos direitos humanos do Estado brasileiro, esta temática dos direitos de LGBT aparece, pela primeira vez, em 1996, quando da primeira versão do Programa Nacional de Direitos Humanos (PNDH) e em 2002, no PNDH2, obtendo um salto na questão dos direitos de LGBT.

O Brasil foi signatário da inclusão do debate sobre a sexualidade na agenda do regime internacional dos direitos humanos, no reconhecimento dela como esfera legítima e fundamental na constituição da individualidade e no exercício da liberdade. Justamente, em 2011, em Durban, na Conferência Mundial contra o Racismo, a Discriminação Racial, a Xenofobia e as Intolerâncias Correlatas, apesar de não ter sido deliberado nenhuma resolução sobre

\footnotetext{
${ }^{4}$ São vários os relatórios sobre violências, apesar do pioneirismo do GGB, há outras fontes. Frente o limite e o foco do trabalho, não trataremos do tema. Contudo, segundo os levantamentos, hoje, a cada 16 horas uma pessoa LGBT é assassinada ou se suicida vítima de LGBTfobia, fazendo o país ser o campeão mundial desse tipo de crime. O aborto do Sistema Nacional de Promoção de Direitos e Enfrentamento à Violência contra LGBT (Sistema Nacional LGBT) é fato histórico, apesar dos problemas e equívocos em sua implementação nos estados.
} 
discriminação por orientação sexual, produziu discussões que foram adensadas em 2003, quando $\mathrm{O}$

Debate possibilitou que o governo brasileiro apresentasse à Comissão de Direitos Humanos das Nações Unidas (...) uma proposta de Resolução tendo como objeto a discriminação por orientação sexual e identidade de gênero como uma violação de direitos, mesmo que no Brasil ainda não exista uma legislação específica (DUARTE, 2014a, p. 91-92).

Ainda que a "Resolução brasileira" tenha sofrido grande resistência de diversos países e, sem as recomendações necessárias, em torno dela conduziu-se à organização do Painel Internacional de Especialistas em Legislação Internacional de Direitos Humanos, Orientação Sexual e Identidade de Gênero, em 2006, na cidade de Yogyakarta, promovido pela Organização das Nações Unidas (ONU).

Assim, como resultado, surge Os Princípios de Yogyakarta para Aplicação de Direitos Humanos à Orientação Sexual e Identidade de Gênero (ONU, 2006) que sustentam o reconhecimento dos direitos de LGBT no sistema internacional. Trata-se de um documento com 29 princípios sobre as normas de direitos humanos referentes à orientação sexual e identidade de gênero que norteiam a implementação de direitos dos dissidentes sexuais e de gênero.

$\mathrm{Na}$ sequência, em 2011, o Conselho dos Direitos Humanos da ONU adotou uma Resolução que aponta a grave preocupação com ações discriminatórias e violentas motivadas pela orientação sexual e/ou identidade de gênero das vítimas e no ano seguinte, realiza-se o primeiro painel intergovernamental destinado à temática LGBT.

Portanto, como forma de orientar as ações para a ampliação do reconhecimento dos direitos e ao enfrentamento das discriminações, coerções e violências praticadas contra LGBT, lançou-se, em 2012, o livreto e a campanha Nascidos Livres e Iguais: Orientação Sexual e Identidade de Gênero no Regime Internacional de Direitos Humanos. No mesmo sentido, a Organização Internacional do Trabalho (OIT) institui uma Convenção sobre a discriminação no trabalho e na profissão para a população LGBT.

Em mesmo sentido, em 2015, a Organização dos Estados Americanos (OEA), através da Comissão Interamericana de Diretos Humanos, publica um documento que trata da violência contra LGBT nas Américas. No começo de 2018, a Corte Interamericana de Direitos Humanos determina o reconhecimento dos direitos de casais do mesmo sexo e a troca de identidade sexual nos registros civis.

Observa-se, com tudo isso, que o debate, no Brasil, na cena pública LGBT, tem correspondência naquilo que o País é signatário nos marcos internacionais dos direitos humanos de LGBT, apesar da ofensiva conservadora. Portanto, muito dos aspectos da proteção dos direitos civis de LGBT foram aprovados pela Corte brasileira, através do Supremo Tribunal Federal (STF), como: a) o reconhecimento como família da união civil estável entre pessoas de mesmo gênero - casais homoafetivos e o casamento civil igualitário entre pessoas do mesmo gênero; b) retificação do prenome e do sexo/gênero no registro civil não condicionado às exigências de realização da cirurgia de transgenitalização, autorização judicial e laudos médicos e 
psicológicos $^{5}$; c) revoga a restrição de doação de sangue para gays, bissexuais, homens que fazem sexo com homens (HSH), travestis e mulheres transexuais, postas nas normativas do Ministério da Saúde e da Agência Nacional de Vigilância Sanitária (ANVISA); d) a regulação do processo de reprodução assistida e o registro dos filhos gerados através dessas técnicas por casais héteros e homoafetivos; e) a criminalização em decorrência de discriminação por orientação sexual e identidade de gênero, tendo em vista a morosidade e conservadorismo do Parlamento brasileiro em não se ter nenhuma lei específica que trate da homo-transfobia, mas usualmente denominado pelos movimentos sociais LGBT como LGBTfobia.

Em 2008, em função da $11^{a}$ Conferência Nacional de Direitos Humanos, foi possível discutir mais profundamente os direitos LGBT e atualizar o PNDH3, especificando os objetivos estratégicos e suas formas de atuação, contemplando cinco ações programáticas mais objetivas e sistematizadas em prol da garantia do respeito a livre orientação sexual e identidade de gênero, instituído pelo Decreto n ${ }^{\circ} 7.037$, de 21 de dezembro de 2009.

Neste mesmo ano, de forma inaugural, realiza-se a I Conferência Nacional de Políticas Públicas e Direitos Humanos de GLBT. Das 559 propostas consolidadas no Relatório Final, 167 correspondem à área da saúde. No referido documento, temos um total de 166 estratégias de ação, destas, 48 dizem respeito ao campo da saúde. O produto de todas essas deliberações converte-se então no primeiro e único Plano Nacional de Promoção da Cidadania e dos Direitos Humanos de LGBT, em 2009, em território nacional.

Neste período, surge a Coordenação-Geral de Promoção dos Direitos de LGBT, em 2010 e a reconfiguração do Conselho Nacional de Combate à Discriminação (CNCD) e Promoção dos Direitos de LGBT, em 2011. Tem-se institucionalizado o que se denominou de tripé da cidadania LGBT (AGUIÃO, 2018; IRINEU, 2019): o plano, o conselho de direitos e a gestão da política, na forma de coordenadoria, que no âmbito nacional, nessa lógica e estrutura, teve curta existência, até 2019.

Nesse processo, o Ministério da Saúde institui a Política Nacional de Saúde Integral LGBT, que teve como eixo fundante as diretrizes contidas pelo Programa Brasil Sem Homofobia (BSH) do governo federal e foi legitimado na II Conferência Nacional LGBT, em 2011, sem, contudo, apontar para um novo plano nacional de direitos dessa população.

Todos esses acontecimentos que tentam contemplar a construção de um Plano de direitos LGBT parecem frágeis, haja vista a realização da III Conferência Nacional LGBT junto com outras políticas em 2016 e seus desdobramentos, mais uma vez, sem seu produto, um plano. Contudo, isso se deve, não pelas normativas, mas pela efetivação real e concreta da garantia de direitos no processo histórico protagonizado pelos movimentos sociais LGBT. Que ora se ve atrelado e cooptado pelo poder público e com isso se adequa e adere ao assistencialismo do Estado, na forma de uma cidadania de consolação, que reforça a lógica identitária, ou na judicialização da política e dos direitos de LGBT.

Carrara (2010) e na sequência Aguião (2018) nos alertam para esse processo de constituição da cidadanização dos sujeitos LGBT numa crença ao Estado, correndo o risco do investimento na judicialização da política para a garantia de direitos LGBT, se todos dessa

\footnotetext{
${ }^{5}$ Inúmeras leis e/ou decretos estaduais e municipais reconhecem às pessoas transgêneros o direito ao uso do nome social. Na Administração Federal, tal direito é assegurado pelo Decreto Presidencial no 8.727, de 28 de abril de 2016. A Receita Federal do Brasil expediu a Instrução Normativa n ${ }^{\circ} 1718$, de 18 de julho de 2017, autorizando a inclusão do nome social no Cadastro de Pessoa Física (CPF) do(a) contribuinte transexual ou travesti. Além da Resolução Conselho Nacional de Justiça $(\mathrm{CNJ}) \mathrm{n}^{\circ} 270$, de 11 de dezembro de 2018, que adere o uso do nome social no sistema de justiça brasileiro.
} 
população acessassem de forma equânime e igualitária, se não houvesse outros marcadores sociais de diferença e de desigualdades, como classe social, raça, território, dentre outros.

A partir do golpe de Estado, em 2016, as forças conservadoras que antes estavam no pacto de gestão do governo federal, agora dão a direção política e econômica, mantendo a fachada de algumas estruturas no poder público em respostas aos LGBT, mas no seu todo, retrocedeu no pouco e precário que se conquistou em termos de políticas e serviços sociais.

\section{A emergência da saúde LGBT no contexto do SUS}

A saúde, grosso modo, sempre foi campo de luta e uma das principais demandas e reivindicações por políticas e direitos dos movimentos sociais de LGBT, por isso a presença histórica desses sujeitos nesse campo, principalmente, como usuários. Primeiro, em decorrência da ordem médica, considerados loucos e degenerados, submetidos ao tratamento moralpsiquiátrico em instituições manicomiais, com todos os requintes de violência, como isolamento, eletrochoque etc. Em seguida, na luta contra a Aids e por respostas governamentais frente a essa pandemia (FACCHINI, 2005; LEITE JUNIOR, 2011), que até os dias atuais, ainda se faz presente, particularmente, pelo desmonte contemporâneo da política estatal construída nesses quase quarenta anos.

As produções acadêmicas sobre esse campo temático concentraram-se, inicialmente, na antropologia e, em seguida, na saúde coletiva, em especial, com enfoque em seus objetos de estudos - o comportamento dos ditos homossexuais e a prevenção às doenças sexualmente transmissíveis (DST) - e, em particular, no debate que o fenômeno da AIDS/HIV trazia, a partir dos anos 1980, associado, ou às vezes desencontrado, aos estudos feministas acerca dos direitos sexuais e reprodutivos, configurando-se como temas e debates marginais e secundarizados também nessas duas áreas do conhecimento científico (DUARTE, 2014a, p. 78-79).

Desde a $12^{\text {a }}$ Conferência Nacional de Saúde (CNS), realizada em 2003, o tema dos direitos LGBT vinha sendo pautado pelo SUS e, em 2007, na $13^{a}$ CNS, a orientação sexual e a identidade de gênero são incluídas na análise da determinação social da saúde, reafirmadas na $14^{a}$ CNS, em 2011. As seguintes recomendações emanaram destas conferências: “o desenvolvimento de ações intersetoriais de educação em direitos humanos e respeito à diversidade, efetivando campanhas e currículos escolares que abordem os direitos sociais"; "a sensibilização dos profissionais a respeito dos direitos de LGBT, com inclusão do tema da livre expressão sexual na política de educação permanente no SUS”; “ inclusão dos quesitos de identidade de gênero e de orientação sexual nos formulários, prontuários e sistemas de informação em saúde"; "a ampliação da participação dos movimentos sociais LGBT nos conselhos de saúde"; "o incentivo à produção de pesquisas científicas, inovações tecnológicas e compartilhamento dos avanços terapêuticos"; "a garantia dos direitos sexuais e reprodutivos e o respeito ao direito à intimidade e à individualidade"; "o estabelecimento de normas e protocolos de atendimento específicos para as lésbicas e travestis"; "a manutenção e fortalecimento de ações da prevenção das DST/AIDS, com especial foco nas populações LGBT”; “o aprimoramento do Processo Transexualizador” e 
"a implementação do protocolo de atenção contra a violência, considerando as identidades de gênero e a orientação sexual”.

Chama-se a atenção que a discriminação por orientação sexual e por identidade de gênero incidem na determinação social da saúde, ao desencadear processos de sofrimento, adoecimento e morte prematura decorrentes do preconceito, da discriminação e do estigma social ao qual estão expostas LGBT (DUARTE, 2015). Assim, destaca-se que o processo social de saúdesofrimento-doença e cuidado de LGBT não deve ser visto de forma isolado, pois é constitutivo na forma como esses sujeitos são vulnerabilizados pela LGBTfobia.

Neste sentido, a Política Nacional de Saúde Integral de LGBT (PNSI-LGBT), publicado em 01 de dezembro de 2011, através da Portaria GM/MS (BRASIL, 2011), emerge como um conjunto de princípios éticos e políticos expressos que tem como marca o reconhecimento dos efeitos perversos, dos riscos e danos à saúde de LGBT nos processos de discriminação, preconceito, marginalização, exclusão e violências LGBTfóbicas que são submetidas essa população em seus processos de saúde-sofrimento-doença.

A PNSI-LGBT expressa as reivindicações do movimento LGBT e o compromisso do Estado junto ao Ministério da Saúde em reduzir as desigualdades e iniquidades em saúde, remodelando a política de saúde para esse público, no que se refere às ações e serviços em saúde.

Iniquidade corresponde à injustiça, seja como negação da igualdade no âmbito da superestrutura político-ideológica, seja como um produto inerente à própria estrutura social $[\ldots]$ no SUS, universalidade supõe que todos os brasileiros tenham acesso igualitário aos serviços de saúde e respectivas ações, sem qualquer barreira de natureza legal, econômica, física ou cultural. A equidade possibilita a concretização da justiça, com a prestação de serviços, destacando um grupo ou categoria essencial alvo especial das intervenções. E a integralidade tende a reforçar as ações intersetoriais e a construção de uma nova governança na gestão de políticas públicas (PAIM; SILVA, 2010, p.113).

Neste sentido, a PNSI-LGBT vai ao encontro dos princípios do SUS, de atender os cidadãos, de acordo com suas necessidades específicas, regionais, territoriais, étnicas, entre outras, assim como outras políticas existentes, que são as especificidades da saúde humana, de acordo com as necessidades de cada sujeito, tais como tantas outras políticas de saúde setoriais de atenção integral, criança e do adolescente, pessoas com deficiência, adolescentes em conflito com a lei, pessoas privadas de liberdade, população negra, mulher, homem, trabalhador/a, população em situação de rua, idoso, povos indígenas, quilombolas, ribeirinhos e ciganos.

Desta forma, as diretrizes e objetivos da PNSI-LGBT, estão, portanto, voltados para a promoção da equidade em saúde e, ao mesmo tempo, se coloca como uma política transversal às outras políticas do setor, com gestão e execução compartilhadas entre as três esferas de governo, como expressa nos dois Planos Operativos da referida PNSI-LGBT, aprovados pela Comissão Intergestora Tripartite (CIT). O primeiro de 2012 a 2015, através da Resolução CIT n ${ }^{\circ}$ 2, de 6 de dezembro de 2011 e o segundo de 2016 a 2019, através da Resolução CIT no 26, de 28 de setembro de 2017. Esses planos têm como objetivo apresentar estratégias para as gestões federal, estadual e municipal, contribuindo para o enfrentamento das iniquidades para a consolidação do SUS como sistema universal, integral e equânime. 
Acrescenta-se que a PNSI-LGBT deve, por princípio organizativo-institucional, também atuar articulada às demais políticas do Ministério da Saúde, voltadas para as mudanças na determinação social da saúde, com vistas à redução das desigualdades e das vulnerabilidades relacionadas à saúde destes grupos sociais. (BRASIL, 2010).

É nesse sentido que antes propriamente da instituição da PNSI-LGBT, um conjunto de Portarias do Ministério da Saúde que já tinham sido lançadas e que colocavam a presença de LGBT, são incorporadas a referida política de forma direta ou transversal, tais como: a) Portaria GM/MS n. 426, de 22 de março de 2005 (Política Nacional de Atenção Integral em Reprodução Humana Assistida); b) Portaria GM/MS n. 675, de 30 de março de 2006 (Carta dos Direitos dos Usuários da Saúde); c) Portaria GM/MS n. 1.707, de 18 de agosto de 2008 (Processo Transexualizador), substituída e ampliada pela Portaria GM/MS no 2.803, de 19 de novembro de 2013; e d) Portaria GM/MS no 1.820, de 2009 (Direitos e deveres dos usuários da saúde).

Contudo, apesar desse conjunto de legislações, é público, ainda, o desrespeito ao nome social, as várias formas de discriminação, preconceito e marginalização reproduzidas por profissionais da saúde e a barreira de acesso aos serviços de saúde (DUARTE, 2014a). As pessoas trans são as que mais sofrem frente a esse conjunto de questões, em particular, ao buscarem os serviços especializados do processo transexualizador do SUS, além dos casos de transfobia interseccionados com outros marcadores sociais de diferença, levando muitas dessas a abandonarem as consultas e tratamentos (ROMANO, 2008).

Indivíduos e grupos têm grande parte de suas vidas condicionadas por determinantes de diversas naturezas: econômica, política, cultural e subjetiva. Desta perspectiva, as trajetórias de vida de mulheres e homens transexuais constituem a síntese absolutamente singular de suas inserções de classe social, de gênero e "raciais", bem como de suas características culturais, etárias, de seus percursos afetivo-sexuais, entre outras. (ALMEIDA; MURTA, 2013, p. 396).

Assim, como afirmam Rocon, Duarte e Sodré (2018, p. 525),

Ao ser privada do acesso à saúde, a população trans fica fadada aos riscos de sofrimento, adoecimento e morte, uma vez que para a construção do corpo em sintonia com o gênero desejado, em busca da humanização de seus corpos e vidas, vão lançando mão de recursos como silicone industrial, hormônios sem atenção e o cuidado do acompanhamento médico, em alguns casos, podem chegar até ao suicídio.

Assim, se tomarmos especificamente a questão do uso do nome social, como vimos acima, a partir da Carta dos Direitos dos Usuários do SUS, de 2006, garantir esse uso do nome social, no âmbito do SUS, somente, foi possível, a partir de 2009, através da Portaria sobre os Direitos e Deveres dos Usuários da Saúde (BRASIL, 2009), do Ministério da Saúde. Portanto, no cotidiano das práticas de saúde, muitas das vezes esse direito não é garantido no âmbito do SUS, mesmo com a Nota Técnica n. 18/2014, que regulou somente do uso do nome social no cartão do SUS. 
Outra questão que se coloca é sobre a patologização das identidades de gênero trans ou mesmo a concessão estratégia desta mesma (des)patologização. Rocon et al (2016, p. 2524), nessa perspectiva, apontam que:

A seletividade no acesso ao Processo Transexualizador do SUS promovida
pelo diagnóstico precisa continuar sendo discutida. Ainda que a patologização
signifique uma concessão estratégica, a Constituição Federal de 1988 não
condiciona o acesso à saúde no SUS pela existência de uma patologia prévia, e
esse foco na saúde pela negação da doença têm impedido pessoas trans de
acessarem serviços públicos de saúde para assistência e cuidado profissional na
modificação de seus corpos.

Portanto, para além do problema do uso nome social, tem-se os atendimentos desumanizados, dificuldades financeiras, desgastes pela intensa rotina de consultas, ausência e dificuldades de acesso as medicações, as distâncias e deslocamentos dos serviços transexualizadores no SUS, muito destes localizados nas capitais ou cidades de grande e médio portes, dentre outros. Observa-se que são vários os desafios sobre o processo transexualizador e sua efetivação, quando se volta a atenção para a garantia de direitos dos/as usuários/as trans, em particular, no enfrentamento estrutural e institucional de garantia de acesso à atenção e permanência dos cuidados nos serviços de saúde, como hormonioterapia, cirurgias de transgenitalização, mastectomia, histerectomia, plástica mamária, tireoplastia, além de acompanhamentos clínico, psicológico e social (BRASIL, 2013b).

São inúmeros autores que apontam as grandes filas de espera, principalmente, frente as poucas unidades de saúde que contemplam esses serviços e suas linhas de cuidado, como também o processo formativo das equipes interprofissionais e o aprimoramento de técnicas e protocolos clínicos humanizados.

A PNSI-LGBT também tem por base a construção de ações transversais não só em diversas áreas da política de saúde e suas redes de atenção, como na política de educação permanente e da sensibilização das/os profissionais de saúde acerca das especificidades da população LGBT no âmbito do SUS, independente de atuarem em campos específicos que LGBT é comumente presente.

Assim, para além do processo transexualizador, ainda se volta à atenção as pessoas vivendo com HIV/AIDS, nas práticas de educação e saúde, nas políticas de prevenção e promoção da saúde, como no uso do preservativo, na realização do teste rápido e no acesso a PrEP (Profilaxia pré-exposição) e a PEP (Profilaxia pós-exposição). Contudo a PNSI-LGBT influenciou, a partir da nova edição de 2014, a inclusão dos seguintes novos campos da Ficha de Notificação de Violência Interpessoal/Autoprovocada, tais como: nome social; orientação sexual; identidade de gênero da pessoa que foi agredida, bem como também foi incorporado um campo para identificação da violência por motivação de homo/lesbo/transfóbica, como do ciclo de vida do provável autor da agressão.

A PNSI-LGBT também alterou, no Sistema de Informação em Saúde para a Atenção Básica - SISAB (e-SUS AB), a Ficha de Cadastro Individual, que tem agora um campo para o nome social no Prontuário Eletrônico do Cidadão (PEC) e um outro para o preenchimento da identidade de gênero e orientação sexual do usuário do SUS. 
Portanto, observa-se que nesses dez anos de institucionalização a PNSI-LGBT até agora ainda não avançou, como se pretendia, limitado ao papel, com significativa lacuna teórica e um vazio assistencial em se tratando desse tema e seus correlatos, em particular a saúde mental, drogas e a violência epidêmica (DUARTE, 2017). Principalmente, articulado ao campo dos direitos humanos de LGBT, particularmente, em um contexto de enxugamento e congelamento de recursos financeiros por parte da gestão pública do governo federal para com a saúde e as crises que se alargou nos últimos tempos, agudizadas pelo contexto de pandemia da Covid-19 e que afeta as três instâncias de governo e com destaque para a gestão do SUS e o público LGBT (DUARTE, 2020).

\section{Considerações finais}

Nesse capítulo pretendeu-se problematizar histórica e criticamente o percurso e a instituição da política nacional de saúde integral LGBT, em um país que mais mata gays e travestis do que nos trezes países do Oriente e da África onde a pena de morte contra essa população é lei.

Cabe ressaltar que o discurso moralizador-religioso está presente em vários setores da vida social, como o que se tem visto ser propalado nos últimos tempos, a falaciosa "ideologia de gênero" (JUNQUEIRA, 2017), que emerge, mundialmente, como um projeto político neoconservador numa ofensiva antiLGBT, anti-feminismo e antigênero (PRADO; CORREA, 2018). Esses continuam a defender a "cura" de LGBT em locais de tratamento próprio, sob a égide de um tipo de cuidado baseado na perspectiva ideológica-religiosa, no mesmo lugar que alguns usuários de drogas de uso prejudicial são tratados, particularmente negros e pobres, as ditas comunidades terapêuticas, que tem, como terapêutica, a conversão e os trabalhos forçados metamorfoseado de laborterapia, por considerarem esses sujeitos abjetos (BUTLER, 2015).

Ao nosso ver, há um entendimento difuso e com um conteúdo conservador sobre a existência de uma política de saúde voltada exclusivamente para os setores vulneráveis, em particular, para a população LGBT e que o Estado brasileiro precisa, a partir do SUS, acolher, atender, cuidar, garantir acesso, permanência e direito à saúde, em todos os níveis, da atenção primária à saúde à alta complexidade, passando pelos quesitos e campos sobre assuntos e temas pertinentes a esse público, como também em todas as redes temáticas e programáticas.

Registra-se que já estamos para completar dez anos da PNSI-LGBT, desde a institucionalização dessa política e ainda há um total desconhecimento e não implantação nas esferas estaduais e municipais do território nacional. Inclusive na gestão atual do governo federal para o âmbito dessa política, através do Ministério da Saúde, o que se percebe é o desinteresse político em sustentar não só essa, mas todas as políticas equitativas, na extinção dos referidos comitês, na não realização de novos cadastramentos e credenciamentos de unidades de saúde para operar a PNSI-LGBT e em particular o processo transexualizador do SUS etc. Nesse embate, portanto, tem-se visto emergir e/ou sustentar as políticas estaduais e municipais de saúde LGBT e o que isso implica, com relação a financiamento, estrutura etc. no sentido de implantar, implementar ou resistir uma política de saúde LGBT em tempos ultraconservadores e de desmonte das políticas públicas.

A luta pela saúde da população LGBT e particularmente de pessoas trans não pode ser descolada do movimento pela efetivação, sustentação e defesa de um SUS público, universal e 
equânime, no sentido de se garantir a saúde de LGBT pelo Estado brasileiro. É neste sentido, portanto, que observamos, na conjuntura atual, o desmonte da referida política em âmbito nacional e a remanicomialização das dissidências sexuais e de gênero, pelos setores conservadores, cada vez mais financiados pelo mesmo Estado ultraneoliberal.

\section{Referências}

ALMEIDA, G.; MURTA, D. Reflexões sobre a possibilidade da despatologização da transexualidade e a necessidade da assistência integral à saúde de transexuais no Brasil.

Sexualidad, Salud y Sociedad, Rio de Janeiro, n. 14, p. 380-407, ago. 2013.

AGUIÃO, S. Fazer-se no "Estado": uma etnografia sobre o processo de constituição dos "LGBT" como sujeitos de direitos no Brasil contemporâneo. Rio de Janeiro: EDUERJ, 2018.

BENTO, B. A (re)invenção do corpo: sexualidade e gênero na experiência transexual. Rio de Janeiro: Garamond, 2006.

BENTO, B. O que é transexualidade. São Paulo: Brasiliense, 2008.

BENTO, B. Transviad@s: gênero, sexualidade e direitos humanos. Salvador: EDUFBA, 2017.

BORRILLO, D. Homofobia: história e crítica de um preconceito. Belo Horizonte: Autêntica Ed., 2010.

BRASIL. Conselho Federal de Medicina. Resolução no 2.265, de 20 de setembro de 2019. Brasília, DF: CFM, 2019.

BRASIL. Conselho Federal de Serviço Social. Resolução no 845, de 26 de fevereiro de 2018. Dispõe sobre atuação profissional do/a assistente social em relação ao processo transexualizador. Brasília: CFESS, 2018.

BRASIL. Comissão Intergestores Tripartite, Ministério da Saúde. Resolução $\mathbf{N}^{\mathbf{0}} \mathbf{2 6}$, de 28 de setembro de 2017 - Estabelece estratégias e ações que orientam o II Plano Operativo da PNSILGBT (2016-2019). Brasília, DF: Ministério da Saúde, 2017.

BRASIL. Ministério da Saúde. Portaria GM/MS no 1.271, de 6 de junho de 2014. Define a Lista Nacional de Notificação Compulsória de doenças, agravos e eventos de saúde pública nos serviços de saúde públicos e privados em todo o território nacional. Brasília, DF: Ministério da Saúde, 2014.

BRASIL. Relatório de violência homofóbica no Brasil: ano 2013. Brasília: Ministério da Justiça, Brasília, 2013a. 
BRASIL. Ministério da Saúde. Portaria nº 2.803, de 19 de novembro de 2013. Diário Oficial da União, Brasília, DF, 21 nov. 2013b. Seção 1, p. 25-30.

BRASIL. Comissão Intergestores Tripartite, Ministério da Saúde. Resolução $\mathbf{N}^{\mathbf{0}} \mathbf{2}$, de $\mathbf{6}$ de dezembro de 2011 - Estabelece estratégias e ações que orientam o I Plano Operativo da Política Nacional de Saúde Integral de LGBT (PNSI-LGBT) - 2012-2015. Brasília, DF: Ministério da Saúde, 2011.

BRASIL. Ministério da Saúde. Portaria GM/MS Nº 2.836, de $1^{\circ}$ de dezembro de 2011. Institui, no âmbito do Sistema Único de Saúde (SUS), a Política Nacional de Saúde Integral de Lésbicas, Gays, Bissexuais, Travestis e Transexuais (Política Nacional de Saúde Integral LGBT). Brasília, DF: Ministério da Saúde, 2011.

BRASIL. Conselho Federal de Serviço Social. Resolução Nº 615, de 08 de setembro de 2011. Dispõe sobre a inclusão e uso do nome social da assistente social travesti e do(a) assistente social transexual nos documentos de identidade profissional.

BRASIL. Conselho Federal de Medicina. Resolução no 1.955, de 3 de setembro de 2010. Diário Oficial da União, Brasília, DF, 3 set. 2010, Seção 1, n. 170, p. 109-110.

BRASIL. Presidência da República. Decreto no 7.037, de 21 de dezembro de 2009. Diário Oficial da União, Brasília, DF, 22 dez. 2009, Seção 1, p. 17

BRASIL. Ministério da Saúde. Conselho Nacional de Saúde. Relatório final da 13 $^{\text {a }}$ Conferência Nacional de Saúde. Brasília: Ministério da Saúde, 2008.

BRASIL. Ministério da Saúde. Portaria no 1.707, de 18 de agosto de 2008. Diário Oficial da União, Brasília, DF, 19 ago. 2008. Seção 1, p. 43.

BRASIL. Conselho Federal de Serviço Social. Resolução nº 489, de 3 de junho de 2006. Diário Oficial da União, Brasília, DF, 3 jun. 2006, Seção 1, p. 80.

BRASIL. Ministério da Saúde. Conselho Nacional de Combate à Discriminação. Brasil sem homofobia: Programa de Combate à Violência e à Discriminação contra GLTB e Promoção da Cidadania Homossexual. Brasília: Ministério da Saúde, 2004.

BRASIL. Conselho Federal de Medicina. Resolução no 1.652, de 06 de novembro de 2002. Brasília, DF: CFM, 2002.

BRASIL. Conselho Federal de Psicologia. Resolução no 01, de 22 de março de 1999. Brasília: CFP, 1999.

BRASIL. Conselho Federal de Medicina. Resolução no 1.482, de 19 de setembro de 1997. Diário Oficial da União, Brasília, DF, 19 set. 1997, Poder Executivo, p. 20944. 
BUTLER, J. Problema de gênero. 15 ed. São Paulo: Civilizações Brasileiras, 2015.

CARRARA, S. Políticas e direitos sexuais no Brasil contemporâneo. Revista Bagoas - Estudos gays: gênero e sexualidade, Natal, v. 4, n. 5, p. 131-147, nov., 2010.

CARRARA, S.; VIANNA, A. "Tá lá o corpo estendido no chão": a violência letal contra travestis no município do Rio de Janeiro. Physis, Rio de Janeiro, n. 16, v. 2, p. 233-249, 2006.

DUARTE, M. J. de O. Dissidências sexuais, vidas precárias e necropolítica: impressões de uma experiência em tempos de pandemia. In: OLIVEIRA, A, D. (Org.). População LGBTI+, vulnerabilidades e pandemia da COVID-19. Campinas: Saberes e Práticas; Papel Social, 2020.

DUARTE, M. J. de O. Diversidade sexual e de gênero e saúde mental: Enlaçando políticas e direitos. In: PASSOS, R. G.; COSTA, R. de A.; SILVA, F. G. da (Org.). Saúde Mental e os desafios atuais da atenção psicossocial. Rio de Janeiro: Gramma, 2017.

DUARTE, M. J. de O. Cuidado de si e diversidade sexual: capturas, rupturas e resistências na produção de políticas e direitos LGBT no campo da saúde. In: RODRIGUES, A; DALLAPICULA, C; FERREIRA, S. R. da S. (Org.). TransPosições: lugares e fronteiras em sexualidade e educação. Vitória: Ed. UFES, 2015.

DUARTE, M. J. de O. Diversidade sexual, políticas públicas e direitos humanos: saúde e cidadania LGBT em cena. Temporalis. Brasília (DF), ano 14, n. 27, p. 77-98, jan./jun. 2014a.

DUARTE, M. J. de O. Saúde, cuidado e diversidade sexual: a temática da transexualidade na atenção básica em saúde. In: COELHO, M. T. Á. D.; SAMPAIO, L. L. P. (Org.).

Transexualidades: Um olhar multidisciplinar. Salvador: Ed.UFBA, 2014b.

DUARTE, M. J. de O. Diversidade sexual e Política Nacional de Saúde Mental: contribuições pertinentes dos sujeitos insistentes. Em Pauta, Rio de Janeiro, n. 28, vol. 9, p. 83-115, dezembro de 2011.

FACCHINI, R. Sopa de Letrinhas?: movimento homossexual e produção de identidades coletivas nos anos 90. Rio de Janeiro: Garamond, 2005.

FOSTER, D. W. Consideraciones sobre el estudio de la heteronormatividade en la literatura latinoamericana. Letras, Santa Maria, n. 22, p. 49-53, jan./jun. 2001.

FOUCAULT, M. Nascimento da biopolítica. São Paulo: Martins Fontes, 2008.

FOUCAULT, M. História da sexualidade. v. 1. 7 ed. Rio de Janeiro: Graal, 1988.

FOUCAULT, M. História da loucura na idade clássica. São Paulo: Editora Perspectiva, 1978. 
GRUPO GAY DA BAHIA (GGB). Mortes violentas de LGBT no Brasil: Relatório 2019. Salvador: GGB, 2020. Disponível em: https://grupogaydabahia.com.br/relatorios-anuais-demorte-de-lgbti/. Acesso em: 02 maio 2021.

IRINEU, B. A. Nas tramas da política pública LGBT: um estudo crítico acerca da experiência brasileira (2003-2015). Cuiabá: Ed. UFMT, 2019.

JUNQUEIRA, R. D. "Ideologia de gênero": a gênese de uma categoria política reacionária - ou: como a promoção dos direitos humanos se tornou uma "ameaça à família natural". In: RIBEIRO, P. R. C.; MAGALHÃES, J. C. (Org.). Debates contemporâneos sobre educação para a sexualidade. Rio Grande: Ed. FURG, 2017.

LEITE JUNIOR, J. Nossos corpos também mudam: a invenção das categorias “travesti” e "transexual" no discurso científico. São Paulo: Annablume; FAPESP, 2011.

LOURO, G. L. Um corpo estranho: ensaios sobre sexualidade e teoria queer. Belo Horizonte: Autêntica, 2004.

MACRAE, E. A construção da igualdade: identidade sexual e política no Brasil da Abertura. Salvador: Ed UFBA, 2018.

ONU. Princípios de Yogyakarta, 2006. Rio de Janeiro: SPW, 2007.

PAIM, J. S.; SILVA, L. M. V. Universalidade, integralidade, equidade e SUS. BIS - Boletim do Instituto de Saúde, São Paulo, v. 12, n. 2, p. 109-114, ago., 2010.

PRADO, M. A. M. et al. Análise da Resolução CFM 2265, de 20 de setembro de 2019. Belo Horizonte, NuH-FAFICH-UFMG, 2020. Disponível em:

https://www.fafich.ufmg.br/nuh/2020/01/24/analise-da-resolucao-cfm-2265-de-20-desetembro-de-2019/. Acesso em: 28 abr. 2021.

PRADO, M. A. M.; CORREA, S. Retratos transnacionais e nacionais das cruzadas antigênero. Revista Psicologia Política, São Paulo, v. 18, n. 43, p. 444-448, dez., 2018.

RICH, A. Heterossexualidade compulsória e existência lésbica. Bagoas - Estudos gays: gênero e sexualidade, Natal, v. 4, n. 5, p. 17-44, jan.-jun., 2010.

ROCON, P. C., DUARTE, M. J. de O.; SODRÉ, F. Questões para o trabalho profissional do Assistente Social no processo transexualizador. Katálysis, Florianópolis, v. 21, n. 3, p. 523-533, set./dez. 2018.

ROCON, P. C. et al. Dificuldades vividas por pessoas trans no acesso ao Sistema Único de Saúde. Ciência \& Saúde Coletiva, Rio de Janeiro, v. 21, n. 8, p. 2517-2526, 2016. 
ROCON, P. C. Clínica (trans)sexualiza(dor)a: processos formativos de trabalhadores da saúde. Salvador, Editora Devires, 2021.

ROMANO, V. F. As travestis no Programa Saúde da Família da Lapa. Saúde e Sociedade, São Paulo, v. 17, n. 2, p. 211-219, abr./jun. 2008.

SCOTT, J. W. Gênero: uma categoria útil de análise histórica. Educação \& Realidade. Porto Alegre, vol. 20, n. 2, p. 71-99, jul-dez, 1995.

SIMAKAWA, V. V. Por inflexões decoloniais de corpos e identidades de gênero inconformes: uma análise autoetnográfica da cisgeneridade como normatividade. 2015. 244f. Dissertação (Mestrado em Cultura e Sociedade) - Instituto de Humanidades, Artes e Ciências Professor Milton Santos, Universidade Federal da Bahia, Salvador, 2015. 